\title{
Programa e Projeto como Paradigmas \\ Epistemológicos da Comunicação
}

LUCRÉCIA D'Alessio FerRara

Pós-Graduação em Comunicação e Semiótica - PUCSP 


\section{Resumo}

Dividido em quatro itens, este trabalho propõe o estudo da epistemologia da comunicação que se desenvolve como decorrência de duas categorias básicas: o programa e o projeto. Como a comunicação enquanto prática e teoria surge confundindo-se com o auge do Modernismo na segunda metade do século XIX e, sobretudo, na primeira metade do século XX, é ponderável perceber que existe entre eles forte vínculo programático com características que fazem com que a comunicação repita tendências básicas da ciência ocidental. Confrontando-se com o Modernismo, surge a modernidade que se caracteriza não como programa, mas como projeto teleológico cultural e científico que sugere à epistemologia da comunicação enfrentar o desafio de uma indeterminação ontológica entendida, não como insuficiência ou fraqueza científica, mas como característica da realidade social e tecnológica que atinge a comunicação dos nossos dias. Programa e projeto assinalam duas poderosas categorias para epistemologia da comunicação e salientam a sua indispensável reflexão para que se alcance definir a comunicação dos nossos dias enquanto campo complexo ético e estético.

\section{Palavras-chave}

programa, projeto, Modernismo, Modernidade, comunicação, epistemologia, campo científico.

\section{Abstract}

Divided in four topics, this paper will outline the reflection epistemology communication based on two scientific categories: program and project. Practical and theory communication began at the XIX century, but his development occurs at the begin XX century, in this period it is possible to find a very strong link between modern movement and communication: both repeat basics tendencies occidental culture and science to the program activities. In comparison to modern movement, will outline modernity who characterizes himself not like a program 
but a teleological cultural and scientific project to suggest communication one ontological indeterminableness. This relative or indeterminate identity communication it is link contemporary technological and social reality. Program and project will be marks two very strong epistemological categories to characterize communication how complex ethical and aesthetic scientific field.

Key words

communication epistemology, modern movement, modernity, program, project, scientific field.

\section{Dividir para ordenar}

$\mathbb{M}$ ais do que a obra, o título, Apocalípticos e Integrados (Eco, 1964), sintetiza uma epistemologia da ciência ocidental e de um pensamento ancestral, responsável por uma tendência cultural que sintetiza a tensão dicotômica entre apocalípticos e integrados. Ou seja, não nos interessa, no momento, voltar às questões relativas à cultura de massa tratadas por Eco naquela obra, mas perceber uma questão básica inerente àquela dicotomia: de um lado, os integrados produzem os próprios objetos da cultura de massa, de outro lado, os apocalípticos produzem a teoria daquela cultura; os primeiros operam no âmbito da produção da cultura, os segundos tratam dela teoricamente.Conforme salienta o próprio Eco na Introdução ao seu trabalho "Anche perché se gli apocalittici sopravvivono proprio confezionando teorie sulla decadenza, gli integrati raramente teorizzano e piú facilmente operano, producono, emettano i loro messaggi quotidianamente ad ogni livello" (Eco, 1964: 6) 
A tensão evidenciada por Eco entre apocalípticos e integrados é análoga à que ocorre entre os que produzem os objetos materiais de uma cultura e aqueles que se ocupam da dimensão epistemológica daquela produção, dicotomia presente e constante na questão que converge para a divisão banal entre teoria e prática. Portanto, o título da obra de Eco só nos interessa porque aponta para uma tendência básica da cultura ocidental: na ânsia de construir a unidade, produz dicotomias.

A ancestral divisão entre teoria e prática gera, de um lado, uma tendência que limita as possibilidades do conhecimento na medida em que o afasta da experiência como fonte de conhecimento e da sua possibilidade real, de outro lado, procura criar relações entre causas e efeitos dando-lhes uma funcionalidade linear e necessária. Desse modo, a teoria busca relações homogêneas para ser possível estabelecer princípios gerais e estáveis, mas essa identidade cria-lhe os obstáculos que decorrem do encontro inevitável com a experiência e suas diferenças.

Essa tendência à elaboração de princípios gerais e estáveis permite à ciência criar alguns princípios epistemológicos básicos: ao lado da inequívoca relação entre sujeito/objeto do conhecimento que constitui a base epistemológica da ciência, está a dimensão coletiva e social da produção científica de onde decorre a relação de troca e de cooperação que sustenta a sua base opinativa. Sob essa comunicação cooperativa, aquela relação sujeito/objeto do conhecimento procura encontrar bases estáveis ou controladas que, na cultura ocidental, se apóiam mais sobre o sujeito e suas decisões de conhecimento, do que sobre as oscilações do objeto.

Se entendermos que aquele "acordo de opiniões"(Peirce V:375) justifica e orienta os rumos da produção científica, é necessário entender também, que a hegemonia do sujeito sobre o objeto é a única possibilidade de criar princípios gerais e estáveis. Desse modo, a epistemologia parece decorrer de um paradoxo: confrontam-se $o$ sujeito e o objeto, o homogêneo e o heterogêneo, o geral e o particular, a teoria e a prática, a ciência e a experiência. A epistemologia da comunicação não foge a essa tendência da cultura ocidental, mas pergunta-se: como aquela tendência pode atingir ou tem atingido a 
comunicação e sua epistemologia? A procura por uma possível resposta para esta questão nos impele a percorrer, ainda que de modo resumido, alguns momentos básicos da história do pensamento ocidental a fim de apreender as manifestações que nos permitiriam inferir os traços básicos daquela epistemologia.

Resgatando uma sugestiva interpretação de Argan(1992:251) que, no contexto da atividade técnica e tecnológica, confronta as dimensões epistemológicas que se encontram nas diferenças entre projeto e programa, levantamos como hipótese que aquela distinção pode nos fornecer elementos de reflexão sobre uma epistemologia da comunicação:

O projeto ainda é um processo integrado numa concepção do desenvolvimento da sociedade como devir histórico; a programação, por sua vez, apresenta-se como a superação da história enquanto princípio de ordem da existência social

Entre programa e projeto confrontam-se a razão e a imaginação e, historicamente, o modernismo e a modernidade. Duas experiências vitais para o mundo ocidental e para sua produção de conhecimento. Neste trabalho, estudaremos como o projeto e o programa se confrontam no Modernismo e na Modernidade e como podem estabelecer uma tendência epistemológica para a produção de conhecimento em geral e, sobretudo, na comunicação. Entretanto, dada a complexidade que as caracterizam, não estudaremos as realizações econômicas, políticas, sociais e culturais do Modernismo e seus vários e renomados estudiosos que se autodenominam modernistas, anti-modernistas ou pós-modernistas.

A aproximação entre comunicação, Modernismo e Modernidade não nos parece infundada se considerarmos que a noção de comunicação surge no complexo cultural e tecnológico que assinala a segunda metade do século XIX e encontra seu desenvolvimento na altura da década de 40 do século XX. No século XIX, como decorrência das possibilidades de supressão da distância com o desenvolvimento dos sistemas de transportes, com o adensamento 
populacional em cidades, com as novas formas produtivas e, no século $\mathrm{XX}$, com as duas guerras mundiais, as experiências de Hiroshima e Nagasaki e os desenvolvimentos tecnológicos de mídias de comunicação à distância. Aquela noção surge no cerne da ideologia modernista que, enquanto programa, atinge mais ou menos profundamente todas as dimensões culturais e sociais e, nelas, a comunicação.

\section{A permanência e o movimento: o desafio da modernidade}

Desde Heráclito, o mundo grego enfrentou, com inúmeros malabarismos intelectuais presentes nas suas filosofias e nas suas lógicas, um grande obstáculo que se concentrava na matéria dominada pela transformação ou na ingente necessidade de controle desse movimento. Nos dois casos, uma só questão que se subdivide em: como controlar o movimento? Que realidade ou vida subjaz ao movimento e se revela na sua evolução?

Qual a consequência do movimento?

Entre os pré-socráticos, Heráclito e Parmênides (Sobre a Natureza) sintetizam as duas tendências em oposição: o mundo está em movimento e, no seu fluxo, é impróprio ao conhecimento que exige ordem e estabilidade ou o conhecimento será possível se encontrarmos parâmetros de inteligibilidade que organizem o mundo no seu movimento? As filosofias clássicas de Platão e Aristóteles consolidam duas lógicas que, embora se oponham ontologicamente, procuram maneiras de superar o movimento e criar ordens capazes de permitir o conhecimento. A cosmologia geocêntrica representa a adesão a essa realidade planetária estável que a Idade Média não teve dificuldades em incorporar às suas premissas teológicas judaicocristãs visto que não feria o dogma de um Deus criador do homem e do mundo à imagem e semelhança da sua perfeição. A ciência confundia-se com o religioso e o mítico.

$\mathrm{Na}$ Renascença do século XVI com Copérnico à frente, o mundo já não era o mesmo. Num universo heliocêntrico, o planeta, 
deslocado da posição central, apresentava-se vulnerável e enfraquecido, era urgente criar uma nova centralidade capaz de controlar o tempo, o espaço e a natureza. Essa centralidade foi ocupada pela razão que, apoiada na abastração matemática e geométrica, deu ao homem outro poder capaz de reequilibrá-lo no planeta, embora o valor mítico e religioso acabasse por ser completamente substituído pelo poder laico.

É nesse panorama racionalista que encontramos as raízes da modernidade que abandonava o plano mítico e religioso para aderir à razão técnica, à sua capacidade inventiva e, sobretudo, à tenacidade expansionista que levava a Europa a expandir-se para o além-mar com a mesma desenvoltura com que projetava um espaço abstrato e ideal que poderia ser construído pela geometria euclidiana e pelo rigor da perspectiva. $\mathrm{O}$ tempo era controlado pelo homem e o espaço se deixava organizar e dominar. O projeto da modernidade surge no auge da Renascença e é dominado por um estado de espírito com ideais a serem esteticamente atingidos. Não adimira que surjam nessa época grandes utopistas como Thomas Morus (Utopia, 1516) ou Tommaso Campanella ( Cidade do Sol, 1633) que colocavam o projeto de uma sociedade livre como ideal estético e ético pragmaticamente visível na fábula e na alegoria. A Modernidade da Renascença tinha como base esse "telos" que estruturava seu projeto cultural, técnico, político e social.

Os séculos XVIII e XIX transformaram esse projeto em um programa de valores e de ações e isso significou transformar aquela teleologia em uma estrutura funcional, ao telos e objetivo ideais, acrescentou-se uma dimensão de arquétipo e de realização total do projeto histórico da humanidade e, sobretudo, uma estrutura de fins para os quais a humanidade tendia inexoravelmente e se propunha como modelo progressivo. Entendendo essa funcionalidade como meta a ser atingida, vários momentos históricos da primeira metade do século $\mathrm{XX}$ definiram o alcance desse objetivo como fim da história. O iluminismo do século XVIII está na base dessa proposta de modernização radical e transformou o projeto teleológico da Renascença em programa e destino que o século XIX concretizou e traduziu em turbilhão que Berman sintetiza com veemência: 
Ser moderno é encontrar-se em um ambiente que promete aventura, poder, alegria, crescimento, autotransformação e tranformação das coisas em redor mas ao mesmo tempo ameaça destruir tudo o que temos, tudo o que sabemos, tudo o que somos. A experiencia ambiental da modernidade anula todas as fronteiras geográficas e raciais, de classe e nacionalidade, de religião e ideologia: nesse sentido, pode-se dizer que a modernidade une a espécie humana. Porém é uma unidade paradoxal, uma unidade de desunidade: ela nos despeja a todos num turbilhão de permanente desintegração e mudança, de luta e contradição, de ambigüidade e angústia. Ser moderno é fazer parte de um universo no qual, como disse Marx, "tudo que é sólido desmancha no ar" (Berman, 1987:15)

No âmago do século XIX e na efervescência do programa modernista do século das luzes, colocou-se em questão a teleologia renascentista e essa realidade nos interessa do ponto de vista epistemológico.

\section{A ciência do fim como causa: a questão epistemológica}

A meta-narrativa modernista estrutura um alvo progressista e determinado que, funcionalmente, cria os meios adequados aos seus fins, justificando-os e valorizando-os. Desse modo, o fim parece ser controlado como uma crença a ser concretizada porque prevê o objetivo a ser alcançado, nesse caso, a crença é uma disposição para agir tendo em vista o fim a atingir, uma crença dominada pela sua causação final. Porém, a passagem epistemológica do abstrato para o concreto, do conceito para a observação empírica, da razão para a experiência coloca em questão aquela estrutura funcional de modo que os meios justificam-se por si próprios e, mais do que os fins a alcançar como metas programadas, propõe efeitos possíveis, mas indetereminados e involuntários. (Engel, 2004) 
Se a meta determinada e programada circunscreve à história o caminho do progresso que lhe é inerente, os meios se propõem como mudança sem objetivos e, portanto, sujeito a descaminhos, imprevistos e violações de continuidade. No melhor estilo pragmático, opõem-se, de um lado, a causação final como elo que atua mecânicamente em uma cadeia de ações e leva a um fim iluminado e, de outro lado, a causa eficiente que, da antiga tradição aristotélica, atinge a modernidade como ativo estímulo para a mudança. (Hulswit, 1998: 43-73)

A História das Teorias da Comunicação (Mattelart, 1999) evidencia o impacto daquela causação final que se desenvolve da Escola de Chicago à indústria cultural, à comunicação de massa e à comunicação global, via mídia eletrônica. Em todos esses momentos, procura-se identificar a comunicação com a sua funcionalidade, com aqueles objetivos ou fins para os quais ela serve como instrumento de controle, ordem ou persuasão. Desse modo, temos uma funcionalidade instrumental que pouco ou nada pode sugerir ao desenvolvimento de uma epistemologia ou à definição de um campo científico. Além disso, essa causação final parece estimular um debate instrumental sobre a eficiência objetiva dos meios e estratégias comunicativas, possibilitadas, ou não pela tecnologia. Esta eficiência acaba por atrair a produção da área e confunde-se ciência e reflexão com produtos técnicos ou com descrição da suas características portanto,confunde-se comunicação com tecnologias da comunicação. Inibe-se o debate epistemológico de uma ciência que se encontraria no cerne daquela funcionalidade para ultrapassa-la e supera-la criticamente:

el discurso y la accion sobre la comunicacion, desde mediados de los años ochenta parecen haber multiplicado em tal medida las posturas y posiciones desde las cuales se puede investigar la comunicacion, que el debate es cada vez más difícil, al haber menos referentes comunes. (Navarro, 2003:33)

Nesta identidade funcional, observa-se como a comunicação enquanto técnica é herdeira da dinâmica progressista do Modernismo 
enquanto programa social e da sua metateoria, enquanto postura epistemológica.

Contra o "telos" progressista que funcionalmente submete ações, comportamentos e cotidiano à alavanca inexorável de suas metas, a mudança propõe o fluxo do tempo e do espaço que substitui o cotidiano pelo bom senso e permite escolher entre alternativas e propor novas seleções enquanto informação e impensadas enquanto comunicação, mas com claras tonalidades epistemológicas contra 0 programa de causação final.

A base crítica dessa epistemologia se oferece como alternativa à rotina progressista do Modernismo e contra ela se observa a emergência do fato científico banal e inusitado que sugere associações imprevistas com ritmos e extensões distintos. Conferese ao banal da vida o valor de objeto epistemológico que, sem programações, precisa ser construído em cada observação, em cada análise ou interpretação jamais explicativas e sempre sugestivas. Porém não há como confundir essa epistemologia com a apocalíptica atmosfera pós-moderna que reconhece, apenas, uma sociedade acrítica, amoral e anômica e, como conseqüência, infensa à ciência e à sua possível epistemologia.

Ao contrário, se entendermos que o Modernismo é uma visão de mundo, uma tradução ideológicas com várias decorrências históricas, veremos que a Modernidade é algo que se prolonga desde a Renascença como um estado de espírito que nos permite entender o fluxo do tempo histórico e interpretar, não só, a relação Modernismo e Modernidade, mas sobretudo, sua dimensão epistemológica que supõe superar as normas de um programa, pelas imprevisões de um projeto que, criativamente, vai se revendo e remontando criticamente ante o desafio de cada pequeno fato estudado. Zygmunt Bauman(2001) colocando-se contra as frágeis sínteses pósmodernistas, opõe o Modernismo sólido dos séculos XVIII, XIX e início do XX à Modernidade líquida onde não há perspectivas ou programas de longa permanência, mas onde há um exercício epistemológico enquanto atividade sem ilusões e sem metainstrumentos teóricos, sem totalizações epistemológicas, mas submissa à dialética concreta do seu movimento ao prever totalidades que 
recusam explicações de mão única, como já apontava Karel Kosik (1976:36) em obra antológica e visionária do debate epistemológico da ciência contemporânea.

\section{A indeterminação da epistemologia da comunicação na Modernidade líquida}

Estamos entendendo que na epistemologia da "Modernidade líquida" enfrenta-se com energia o fluxo do tempo no espaço da investigação e a indeterminação é a mais enérgica inspiração epistemológica; portanto, não há temas, teorias aplicativas ou programas de pesquisa sedimentados, ao contrário, cumpre estar atento à comunicação que ocorre nos meandros das interações banais, imprevistas e sem repetições. Essa indeterminação não é uma simples redução semântica do conhecimento, ao contrário, é uma característica epistemológica que acrescenta valor e originalidade à ciência contemporânea, sem relativisa-la ou simplifica-la, como observa Tiercelin (2004: 16) na esteira do pragmatismo de Peirce:

\section{(...) vaguesess which is attached to the impossibility of a strict definition of the domains of application of the concept. For Peirce, this second of form of vagueness is directly tied to ontology and to the hypothesis of the existence of the continuum.}

Ante essa indeterminação, ao mesmo tempo ontológica e epistemológica há, apenas, um projeto atento ao presente que, nas suas conjunções, alarga o território do conhecimento, supera-se, portanto, a repetição do modelo que inibe a invenção e a indústria mecânica utilizou à exaustão. Aquela inibição não só elide a invenção mas sobretudo, a descaracteriza e à sua comunicação, pois não há invenção se não for comunicada. Enquanto programa de ação e valores e enquanto meta-teoria epistemológica, o Modernismo estrutura-se, do ponto de vista científico, como demonstração de certezas que reduz o método à disciplinada dedução e transforma o 
exercício inventivo de elaboração de hipóteses em explicação centrada no sujeito e seus valores que, tautológicos, refletem aquela metateoria. Inibe-se, portanto, a ciência como exercício de fazer ciência. Para uma epistemologia da comunicação como ciência da invenção, é necessário considerar a superação do modelo a fim de caracterizarse como mediação que se dá na história, através dela e, como crítica, apesar dela. O Modernismo enquanto lição histórica nos faz ver que o modelo é um entrave à imaginação científica que, estimulada pelo imprevisto, se desenvolve em processo de seleção, ordenação, avaliação e comparação, etapas indispensáveis para a consecução de uma produção científica, para a definição de um objeto científico e, como conseqüência, de uma série científica que consolida uma área do conhecimento. Desse modo, um objeto científico não é programado, ao contrário é construído na liquidez do processo que o apreende nas suas manifestações imprevistas, embora caiba ao "acordo de opiniões" que consolida uma área cientifica, recolher aquele resultado comparativo para ser possível a caracterização da sua evolução na compreensão do mundo, objeto máximo da ciência e, nela, da comunicação.

Essa atividade pública que constitui o cerne comunicativo do fazer científico transforma aquele "acordo de opiniões", como observa Bourdieu (2004), em livre concurso de relações objetivas entre os pesquisadores de uma área científica e os fazem criar um campo científico no âmbito daquelas relações e determinando-o, portanto, de dentro para fora. Portanto, se o moderno traduz sua necessidade de ordem para tingir metas globais em dicotomias que ressurgem, epistemologicamente, em divisões lineares como causa e consequência ou como parte e todo, a Modernidade, ao contrário, supera aquela estrutura de ordem para sistematizar-se como múltiplo conjunto de tendências em fértil e plural debate. Confrontam-se, portanto, estrutura funcional e sistema aberto à incorporação de constantes re-organizações. Nessa perspectiva, redesenha-se a ciência da comunicação como vigilância epistemológica do acordo que constitui seu campo científico e não se caracteriza como poder e restrição, mas constrói-se como possibilidade. Dessa maneira, o campo se constrói a cada produção científica e o debate epistemológico 
deixa de ser a constatação de que a comunicação não se comunica porque não possui um campo científico. Ao contrário, opondo-se à tradição do programa modernista onde o campo é construído de fora para dentro, na Modernidade líquida o que se busca na produção científica não é o objeto que define territórios de poder, mas o objetivo de construir, em processo, uma área científica que, talvez, resulte frágil do ponto de vista acadêmico, mas cientificamente consequente.

Se a epistemologia da Modernidade exige um alerta científico disponível à apreensão- construção de um objeto impreciso e mutante, a epistemologia da comunicação exige acrescentar àquela vigilância outra atenção voltada às transformações tecnológicas que atingem os meios e os suportes. Aquele incessante avanço altera as mediações comunicativas e multiplica as mídias criando, não raro, um falso objeto científico na medida em que confunde as sintaxes e semânticas daqueles suportes com o próprio objeto da comunicação que, então, é colocado à mercê da indústria cultural, do mercado criado por aquela tecnologia estimulada pelo avanço da globalização comercial, econômica e financeira. Aquela vigilância epistemológica é indispensável a fim de que o objeto da comunicação não perca seu caráter científico e sucumba às veleidades funcionais do mercado (Sodré, 2003:307-308). Desse modo, quando a imprecisão ontológica e epistemológica da Modernidade atinge a comunicação como campo científico, exarceba-se a necessidade daquela vigilância como decorrência da própria fragilidade e mudança a que está sujeita a comunicação situada, ao mesmo tempo, como decorrência tecnológica e como eixo complexo de relações sociais.

A essa experiência de interação comunicativa tecnológica ou não, com o outro se dá o nome de Modernidade, projeto que caracterizaria, mais do que um período histórico, uma adesão epistemológica ao movimento e imprecisão do mundo na medida em que só pode gerar um "pensamento frágil" (Vattimo, 2002 e 1988) sobre a experiência, a técnica, a comunicação, a história enfim. Naquela imprecisão, urge criar um horizonte que, sem chegar a nos estruturar como conhecimento da verdade da comunicação, nos insinua em um campo de possibilidades onde se apreende o objeto que se transforma como a própria história ou a tecnologia, mas não 
nos impede que, com ele, nos movamos como conhecimento, embora entre insegurança e liberdade.

\section{Bibliografia}

ARGAN, Giulio Carlo. "A crise do design" em História da Arte como História da Cidade. São Paulo: Martins Fontes, 1992. . Projeto e Destino. São Paulo: Ática, 2001

BAUMAN, Zygmunt. Modernidade Liquida. Rio de Janeiro: Jorge Zahar, 2001. 1997.

. O Mal-Estar da Modernidade. Rio de Janeiro: Jorge Zahar,

BERMAN, Marshall. Tudo o que é Sólido Desmancha no Ar: a aventura da pós-modernidade. São Paulo: Companhia das Letras, 1987.

Bourdieu, Pierre. Os Usos Sociais da Ciência: por uma sociologia clínica do campo científico. São Paulo: Edunesp, 2004

ECO, Umberto - Apocalittici e Integrati - Milão: Bompiani, 1965

ENGEL, Pascal. Belief as a Disposition to Act: variations on a pragmatist theme - conferência apresentada no 7 . Encontro Internacional sobre o Pragmatismo - Pucsp, 8-11 de novembro de 2004.

HARVEY, David. Condição Pós-Moderna. São Paulo: Loyola, 1992

HERÁCLITO e PARMÊNIDES. "Sobre a Natureza" - em Os Pensadores. São Paulo: Abril Cultural, vol I, 1973.

HULSWIT, Menno. Fron Cause to Causation. London: Kluwer Academic Publishers, 2002.

KOSIK, Karel. Dialética do Concreto. Rio de Janeiro: Paz e Terra, 1976.

MATTELART, Armand e Michèlle. História das Teorias da Cvomunicação. São Paulo: Loyola,1999.

NAVARRO, Raúl Fuentes. "La producción social de sentido sobre la producción social de sentido: hacia la construcción de un marco epistemológico para los estudios de la comunicación" em Epistemologia da Comunicação. São Paulo: Loyola, 2003. 
Programa e projeto como paradigmas epistemológicos...

PEIRCE, Charles Sanders. Collected Papers. 4.ed, Cambridge, Massachusetts: Harvard University Press, 1978. 8 vols.

SODRÉ, Muniz. "Ciência e Método em Comunicação" em Epistemologia da Comunicação. São Paulo: Loyola, 2003.

TIERCELIN, Claudine. Vagueness and the Ontology of Art conferência apresentada no 7. Encontro Internacional sobre o Pragmatismo - Pucsp, 8-11 de novembro de 2004.

VATTIMO, Gianni. As Aventuras da Diferença. Lisboa: Ed. 70, 1988.

.O Fim da Modernidade. São Paulo: Martins Fontes, 2002. 